\title{
Business Intelligence Technology and Marketing Strategy in the Retail Sector
}

\author{
Ezekiel Ochieng Owuor
}

\begin{abstract}
Winnie Njeru
ABSTRACT

Today's world is undergoing unprecedented changes due to increased competition, globalization, demanding customers with diverse tastes and preferences. This growth could be attributed to the declining cost of acquiring and storing very large amounts of data arising from sources such as customer transactions in retail outlets, e-businesses, RFID tags for inventory tracking, email, and product reviews among others. Business Intelligence technology is a recent development in business decision-making, both strategic and tactical, and a key driver of profitability. Critical corporate decisions are now grounded on empirical data which constitute the basis of both descriptive and predictive analytics. The study sought to assess the influence of Business Intelligence technology on marketing strategies of large supermarkets in Nairobi. Supermarkets generate vast amounts of transactional data, which can comprise a source of value when appropriate BI technology is optimally deployed on them to extract potentially strategic information. The study targeted five large supermarkets. The study used a descriptive cross-sectional research design where a structured questionnaire was used to collect pertinent data. Data were analysed using descriptive statistics and logistic regression analysis. The study results indicated minimal use of BI technology by large supermarkets in Nairobi county hence the influence of the same on marketing strategies was not extensive. However, the study established a statistically significant influence of certain aspects of BI technology on marketing strategy of large supermarkets in Nairobi. Despite lack of access to such data, supermarkets employed other components of BI technology such as data warehousing and market basket analysis which were used to some extent for market segmentation. The study recommends that supermarkets should widen their range of BI technologies and sources of data in order to enhance their marketing strategies. The study can be replicated in other service industries.
\end{abstract}

Key words: Business Intelligence technology, marketing strategy Large supermarkets, Kenya

\section{BACKGROUND OF THE STUDY}

Strategic marketing planning translates overall corporate strategy to specific marketing objectives and action plans for implementation. Kotler and Armstrong (1999) argue that company strategy should be concerned with serving the needs of important consumer groups, adding that marketing provides inputs to strategic planning by identifying attractive markets. Traditional, more systematic marketing approaches of data collection relying on a narrow set of data such as age, income and lifestyle are increasingly being replaced by more agile Business Intelligence (BI) technology able not only to gather larger amounts of more diverse data faster, but also generate deeper, broader and more accurate customer insights to inform marketing strategies in line with a turbulent environment (Constantiou \& Kallinikos, 2015). It also provides predictive analysis to allow for timely and effective exploitation of emerging opportunities and avoidance of risk (Nketia, 2016). Firms today collect much larger volumes of customer $\mathrm{m}$ making it challenging for managers to make marketing decisions such as 
personalized offers and services to customers. Today, it is difficult to find a successful enterprise that has not leveraged BI technology for its business.

The study was anchored on Technology Acceptance Model (TAM) Davis (1989) which posits that a system is adopted because of its ease of use and usefulness in performing a task., Resource-Based View (RBV), (Barney, 1991) which postulates that resources have value because through them firms can perform activities that create sustained competitive advantage and and Ansoff's Product/Market Matrix (Ansoff (1957) which suggests ways of growing a business through new and current products, in new or current marketsData is currently viewed as a valuable organizational resource whose wealth-generating capacity can be amplified by analyzing it using BI technology to provide accurate and actionable insight into customers and markets thus providing a competitive advantage.

Kenya's retail and wholesale sector contributes an average of 6.4 per cent annually to the GDP (KNBS, 2017). However, the supermarkets in particular face cut-throat competition from smaller retail outlets and international retail chains venturing into the Kenyan retail market (Mithamo, Marwa \& Leting., 2015). The retail and wholesale market falls under the Economic pillar of Kenya's Vision 2030 which aims at growing the economy at a 10\% per annum.. (Kenya Vision 2030, 2007). While in more developed economies there has been research on leveraging BI technology to develop marketing strategies, such studies in developing countries are limited. In the face of mounting competition from data-driven competitors deploying cuttingedge BI technologies in a global economy premised on knowledge-based intangible assets, there is need to understand the extent of employment of BI technology by large supermarkets in Nairobi county.

\section{Marketing strategy}

Strategic marketing is a process of analyzing market, competitive and business factors impacting the business (Drucker, 1973). This is in addition to identifying opportunities and threats to be addressed and forecasting relevant business trends. Selecting objectives and formulating specific means of attaining them are integral to marketing strategy. Kotler (1997), on the other hand, views strategic marketing as involving the marketing mix-the 4Ps: price, place, promotion and product. The selection of target markets and levels of marketing expenditure, pointing out that marketing strategy is the way in which the marketing function configures its activities to ensure profitable growth in sales. A marketing mix aimed at a target market may involve a quality product with a premium price tag available only at a particular high-end store and advertised exclusively to the target segment.

BI technology can show which outlets or regions are selling either more or less products of particular quality and categorize customers for purposes of informing promotional decisions. If a given segment is buying more products of a specific quality, an advert can be tailored to resonate with consumers of that demographic or psychographic who are currently not shoppers (Kar, et al., 2010). BI can be used to analyze the sales data generated by those who responded to the promotion to determine the extent of the effectiveness of the promotion. Thus BI can both inform strategy (market penetration and/or market development) and evaluate it.

Kotler and Armstrong (2006) argue that in designing a customer-driven marketing strategy, the marketing manager must understand the customers they will serve and how best to serve them. These are essentially questions of market segmentation and customer satisfaction respectively, implying that marketing strategy involves identifying market segments and implementing actions that attract and retain these segments. BI can classify customers 
according to a wide variety of attributes not available to traditional segmentation methods (Sundsøy et al., 2014). If two products are frequently bought together, a recommender BI technology may be deployed to promote one of the products among those buying the other product.

\section{Business intelligence technology}

According to Aanderud and Hall (2011), BI is the way in which firms transform data into actions. Vercellis (2009), from a technical perspective, views BI as a set of methodologies of mathematical models and analyses that exploit available data to generate information useful for complex decision-making processes. This approach highlights the technological complexities underpinning BI operations on the data to yield business insights. Examples of these mathematical and statistical models are classification, clustering, association rules, sentiment analysis, decision trees, social network analysis, regression and artificial neural networks (Khan \& Quadri, 2012).

BI technology also features database technologies like data warehousing, data marts, data lakes and sandbox for organized storage of large amounts of data in a variety of formats such as text, images, numerals, and GIS, hence the variant name "Big Data" for BI technology. These are used for querying and analysis; predictive analytics for forecasting; and dashboards, reports and scorecards for graphical data visualization and performance measurement. Latest BI technologies incorporate easy-to-use graphical user interphases that can be manipulated even by non-IT experts. BI is thus anchored on statistical methods of analysis in addition to cuttingedge algorithms to yield deeper customer insight faster, accurately and efficiently. It can categorize data and show relations between variables. This may provide insight into what products are often bought together and in what quantities (market basket analysis); which brand is preferred over others; and prediction of which products are more likely to be bought at a given time (Kahalekar \& Patil, 2016).

The Institute for Business Intelligence (n.d.) describes BI as the integration of strategies, processes and techniques to generate actionable intelligence of dispersed and inhomogeneous data of an enterprise, the market or competitors. This explanation comprises the concept of integration of strategies, thus suggesting a goal-oriented approach with the implied actions requisite for goal attainment. This demonstrates the centrality of BI to modern data-driven, decentralized, emergent approach to strategy formulation and implementation which echoes Norton and Kaplan's (2006) conceptualization of strategic thinking in a knowledge-based economy. Every knowledge worker can use BI technology to analyze objective data relevant to their functions. In a turbulent fast-changing world, BI technology serves as both feedback and control mechanism that senses market conditions and relays information to decision makers at various levels to act proactively.

\section{Supermarkets in Nairobi County}

Supermarkets in Nairobi differ in size and number of branches. Those with the largest square feet for individual shops also have several branches including in Nairobi, which is the main urban area in Kenya with a 2017 estimated projected population of 4.3 million people (Nairobi City County, 2014). As a commercial hub of East Africa, the city hosts local and foreign business people and professionals, diplomats, and development workers providing a strong demand for higher-priced consumer goods. Retailers positioned to target this well-off segment have outlets located in upper and middle-class neighborhoods where they are the anchor tenants in highend malls. Smaller supermarkets are often located in middle and lower class estates, and tend to have fewer branches of between one and five. They target different market segments such as middle and lower class households. 
The retail sector has continued to attract foreign brands such as Carrefour, Choppies, Shoprite and Game as they seek to expand their operations in a market dominated by locally owned retail chains. This is in addition to industry analysts terming the local formal retail sector as one of those showing greatest potential in Africa and remaining hugely unexploited with only 18\% formal retail outlet penetration (Nielsen, 2015). New entrants-including local brandshave consistently established new stores in the many newly constructed shopping malls in Nairobi. Yet, despite this scramble for a share of the local retail market, home-grown supermarkets have continued to post significant losses and experience difficulties paying their suppliers

Supermarkets collect vast amounts of transactional customer data. This is in addition to personal data collected through loyalty programs that reveal specific product preferences, buying patterns and personal details like residence and telephone numbers, which have potential for direct marketing. However, Manyika, et al. (2011) argue that many organizations lack the talent to gain competitive insights from big data while others do not organize processes and rewards in ways that encourage decision-making founded on data. In a case study of Amazon, Wal-Mart and Tesco, it was found that BI tools helped in finding patterns and possible stock shortages; and informed management decisions in responding to increased demand in addition to discovering shoppers' preferences which guided direct marketing effort (Agarwal, 2014). Despite this potential of customer data to improve marketing effectiveness and profitability, local mainstream Kenyan supermarkets continue to face challenges of a financial and competitive nature. The entrance of new players can be even more disruptive to such established supermarket entities.

Kroger, a U.S. retail chain, deployed BI technology that uses sensors and predictive analytics to feed managers real-time data predicting when and in which stores long lines will happen (Duff \& Phelps, 2016). Before BI deployment, average waiting time for shoppers was four minutes, which reduced to less than thirty seconds. Similarly, a survey by Nketia (2016) to determine the perception of benefits of BI technology at Ghana's National Identification Authority found that $60 \%$ considered facilitation of fast decision-making, $48 \%$ pointed out forecasting, while $40 \%$ considered speeding data mining.

Mbaluka (2013) studied big data management and business value in the banking sector in Kenya and found that only $29 \%$ had implemented or had plans to implement the same. In only $34 \%$ of banks was big data viewed as strategic. Likewise, a study at Equity Bank to establish how the bank can use BI technology to gain strategic value found that, unlike in other departments, marketing decisions were not being informed by BI technology (Kamara, 2014). Sustained adoption and development of BI technology is capable of boosting operating profits by more than $60 \%$ for retail chains that optimally deploy BI (Manyika, et al., 2011). This research sought to establish the extent to which large Nairobi supermarkets employ BI technology in their marketing strategy and was guided by the following question: What is the influence of BI technology on marketing strategy?

\section{LITERATURE REVIEW}

\section{Business Intelligence Technology and Marketing Strategy}

Constantiou et al. (2015) argue that BI technology is revolutionizing the collection and analysis of data intended to inform strategy. Traditional methods required data definition prior to collection through systematic and purposeful processes to address specific information needs: decision-making. BI is thus seen as challenging prescribed approaches to management and strategy, specifically that the data is not collected intentionally, is haphazard, heterogeneous, 
and, often, trivial, and that therefore require existing strategy models and tools to be modified or replaced.

Kahalekar and Patil (2016) observed that predictive analytics component of BI technology has the capability to determine marketing strategies employed by a firm such as only targeting customers with high potential to respond. Similarly, Nketia (2016) asserts that BI technology is a necessity for monitoring operations, taking strategic decisions and for general business success and growth. BI can forecast customer and market changes and help management to anticipate change and act proactively instead of reactively. Kar et al. (2010) also note that based on the outputs of particular data mining tasks, a marketer is capable of drawing a plan for a marketing strategy, hence reliance on BI technology for strategy. For example, cluster analysis may identify the gap between expected and perceived product benefits hence help in product repositioning. Burton et al. (2006) note that the emergence of BI as a top strategic initiative represents increased focus on how organizations can more broadly use and analyze information to positively affect key business objectives including customer retention and market penetration. According to Gieskes (2000), BI activities are vital for strategy formulation. Marketing strategy is viewed as aligning the organization with its environment for optimal performance.

\section{Business intelligence technology and market segmentation}

The advent of BI technology has occasioned real-time dynamic segmentation. Sudhakar et al. (n.d.) reports that one effect of BI technology is the growing dependence on predictive analytics representing a shift from collective segmentation and towards constantly adjusted quantitative models to predict an individual's behavior. Supporting this view, Winston (2014) observes that Naïve Bayes and Artificial Neural Networks (ANN) BI technologies can be used for real-time segmentation for purposes of assigning a new customer to a particular segment while clustering can be deployed for real-time marketing channel identification. In the same vein, Vojtovič et al. (2016) set out to develop a model for real-time segmentation and bahaviour forecasting process. They demonstrated that using this model with sequence clustering BI technology, customers can be assigned segments in real-time based on their different probabilities to buy certain products in future. The segmentation happens upon buying particular items associated with purchasing projected goods.

Bloom (2005), using ANN conducted a study of the international tourist market that visit Cape Town, South Africa, to segment them in order to better track and grasp each segment's changes in behavior and profile over time. The research demonstrated that ANN offers Cape Metro Tourism an opportunity to expand their research horizon to focus on the discovery of new profitable tourist segments. Sundsøy et al. (2014) study assessed the effectiveness of BI technology in conversion rates. The control group was chosen by the MNO's marketers based on five variables the marketers, from experience, considered likely to take up the offer. The most significant variable was the average revenue per user. The treatment group, on the other hand, were chosen based on 350 features derived from subscription metadata and the use of MNO's services in addition to employing a social graph to derive new features. After testing the data against several BI technologies, decision tree was found, based on accuracy and stability, to exhibit better performance as it reliably showed that the three most important predictors for conversion were total spending on data among close social graph neighbors; discretionary monthly expenditure on text; and discretionary monthly number of texts sent. The BI technology outperformed the human marketers' method of segmentation.

Conducting a survey among Dutch business-to-consumer companies, Verhoef et al. (2002) sought to find out the techniques database marketers used for segmentation and the extent to 
which segmentation was employed. They also wanted to establish the prevalence of the use of response modeling for selecting consumers in database marketing and whether the performance of the companies' database analysis activities depended on the employed methods. The survey found that $90 \%$ of the companies employ database segmentation with the aim of target selection while $64 \%$ used it for differentiated pricing and product offers. They also found that $27 \%$ of the companies used segmentation to build predictive models relevant to each segment through mining rules that distinguish between groups with divergent response rates.

In the same vein, Birjandi et al. (2013) sought to segment customers based on the benefit they sought in a shampoo. They employed the BI technique of cluster analysis k-means algorithm and found a meaningful correlation. The variables marital status, family size, education, job, income, consumption and loyalty correlated with benefit sought when purchasing, that is, hygiene, medical, beauty, economic and whether the product was organic. The study rejected the traditional segmentation based on gender and age on selecting and purchasing shampoo, and emphasized the need for collection of more personalized data through digital communication devices to yield finer, more precise narrower segments through techniques such as factor and cluster analysis.

\section{Business intelligence technology and product development}

New product development tended to rely on specific steps from idea generation all the way to market testing and commercialization (Yelkur, et al., 1996). This further developed to leverage advancements in internet technologies which encouraged online collaborative concept development of new product ideas (Soukhoroukova, et al., 2010). In both cases surveys are carried out to determine the existence and level of demand, the nature and size of the market, cultural factors, conditions of usage and lifestyle. In their study, Dyche (2012) reported that retail chain that explored more than a decade's worth of purchase transactions for probable associations between products, and discovered correlations between particular products which informed rearrangements of products. This occasioned a $16 \%$ growth in revenue for every shopping cart within the first month of trial. In this case, the new strategic reconfiguration of product placement can be considered a new service since by so doing the retail chain eased the shopping experience in addition to satisfying shoppers' need for a product they would not have otherwise bought without the new arrangement. In the same vein, a study was carried out to probe the role of BI technology in new product development and the factors responsible for effective implementation of a new product (Redzepovic \& Theodoros, 2015). It was found that companies used BI predictive analytics techniques to understand and predict what users valued in products and consequently tailored products that reflected those values. Respondents reported that when it came to data-driven new product development, greater amount of data resulted in more effective Research and Development.

Similarly, Zhang et al. (2013) studied a case in a Chinese bank which analyzed customer log data from self-service vending machines. Using BI technology of clustering, customers were categorized based on their user requirements which varied widely: some patterns of usage depended on region of origin, age, the nature of business transacted, sensitivity to cost of transaction, time of intense transaction and functionality. For instance, terminals in residential areas were majorly used for payment of bills and taxes. Based on this information, the terminals and user interfaces were redesigned to align with specific type of frequent usage, hence product development. 


\section{Business intelligence technology and market penetration}

Bloom, (2005) in South African demonstrated that the BI technique of Neural Networks could be deployed to enhance penetration into the international tourist market. The technique was used to identify new profitable international tourist segments that do not visit Cape Town, but have a set of behavioral characteristics similar to the tourists frequenting the city. By focusing on attracting international tourists with demonstrated characteristics of those likely to visit Cape Town and who have not yet done so, Cape Metro Tourism engaged in market penetration. The Neural Networks technique identified particular traits of international tourists who visit Cape Town and narrowed their promotions to as-yet non-visitors who were similar with regard to those traits.

In the same vein, a McKinsey report (Brown, Schuler and Sikes, 2012) observes that a leading consumer products manufacturer is using websites and online communities to rally targeted customers to share product and life experiences thus exploiting the power of word-of-mouth advertising to create new sales channels through their customers (Network Analysis). The report notes that the retailer used data analytics techniques such as automated Sentiment Analysis to mine consumer data generated by social media to measure feedback on new marketing efforts in real-time and on the basis of this modified strategies accordingly. Manyika et al (2011) provides another example of Amazon.com which makes use of its recommendation software, a technology based on BI technique of Association Rules, to suggest which other item could be bought for every item a customer buys online (cross-selling), resulting in the retailer reporting that the strategy accounted for up to 30 per cent of sales hence success in market penetration through social media analytics. This view is supported by Ruhi (2014) who advocates for social media analytics to be used in tactical implementation of social media and corporate strategy. According to Leavey (2013), social media includes-in addition to sites like Facebook-forums where people create, share, and exchange information and ideas in virtual communities or networks and comment sections in mainstream media sites. Thus, by deploying Network Analysis to identify those who are highly networked, firms can launch direct marketing aimed at these individuals so that they share information about products and services hence promoting products within their networks through word of mouth.

Collaborative filtering technique based on Association Rules BI technology identifies mutual nodes in social network groups to recommend items to a user based on the rating of the mutual connection ( $\mathrm{Liu}$, et al., 2010). This increases the chances of the target to take up the offer owing to a high likelihood of those sharing a mutual connection having similar preferences. However, Reinartz et al. (2011) point out that one challenge facing supermarkets in less developed economies is gathering comprehensive market intelligence especially from IT-enabled consumer-to-consumer interactions which call for development of IT applications such as real-time listening and online purchasing environments.

\section{Research Design}

\section{RESEARCH METHOD}

The research adopted a descriptive cross-sectional design. Descriptive design was ideal for qualitative variables, which in the current study are BI technology and marketing strategy.

According to Saunders et al. (2009) cross-sectional surveys could seek to expound on how phenomena are related in various firms at a particular point in time. Cross-sectional design was appropriate for this study since the intention was to establish the current extent of usage of BI technology in large supermarkets in Nairobi county and how this influences marketing strategy. 


\section{Population of the study}

The population of study was large supermarkets that had at least a branch in Nairobi and a minimum of four branches nationally. This made the study a census as all supermarkets meeting these conditions. In total, 11 supermarket brands as at August 2017 were surveyed. The choice is because Nairobi is a cosmopolitan capital city with a large population and where major supermarkets have a presence.

\section{Data Collection}

The study used primary and secondary data. Primary data was collected using a structured questionnaire while secondary data was collected from published material. Walliman (2011) notes that questionnaires are particularly ideal for collecting quantitative as well as qualitative data. The questionnaires were administered to marketing managers. In cases where marketing managers were unavailable, the questionnaires were administered to ICT managers as they were likely to be in charge of setting up, configuring and deploying BI technology for the retailer.

\section{Data Analysis}

The data was analyzed using descriptive analysis and inferential statistics. Descriptive analysis shows the distribution of one or more variables among a population, thus facilitating comparison of those variables (Kothari, 2004). Logistic regression was used in establishing the relationship between two or more variables where the dependent variable was nominal (Hosmer, 2000).

Since the dependent variable was nominal (whether a marketing strategy is influenced by BI technology or not), logistic regression was appropriate for the analysis. The function below is thus read as: The Expected value of $y$ given $x$, can be any value depending on the value of $x$ (the independent variable, in this case, presence or absence of BI technology): $\mathrm{E}(\mathrm{y} \mid \mathrm{x})=ß 0+ß 1$.

\section{EMPIRICAL RESULTS}

The number of supermarkets surveyed was 5 out of 11 originally intended for the study. This represents a success rate of $45.45 \%$. A number of those not surveyed objected to providing data citing unease in sharing organizational information. The results It shows that at 67 branches, Nairobi has slightly more than half of all nationwide branches (130) of the participating supermarkets. In terms of years of existence since formation, the mean age of the participating supermarkets was 14.9 years. The oldest, however, had existed for 30 years while the newest had been in service for 2.5 years, hence the range of 27.5 years.

\section{Business Intelligence Technology and Market Segmentation}

The study sought to establish sources of data the supermarkets used to segment the market. The results are presented in Figure 1. Data from market surveys carried out by participating supermarket staff emerged the main source. This was reported by 80 percent of supermarkets surveyed. Transaction data in the supermarket database was the second most popular source of data for segmentation followed by both data in the supermarket data warehouse and data from third party marketing companies, each of which was chosen by 40 percent of the respondents.

Real-time customer data and customer data from supermarket website were each chosen by 20 percent of the respondents. Customer data from supermarket social media was not used for segmentation by any of the supermarkets surveyed. This points to low usage of BI technology in segmentation among the surveyed supermarkets. Sundsøy et al. (2014) observe that BI can 
classify customers based on a diversity of attributes not available to traditional segmentation methods.

Figure 1: Sources of data used for market segmentation

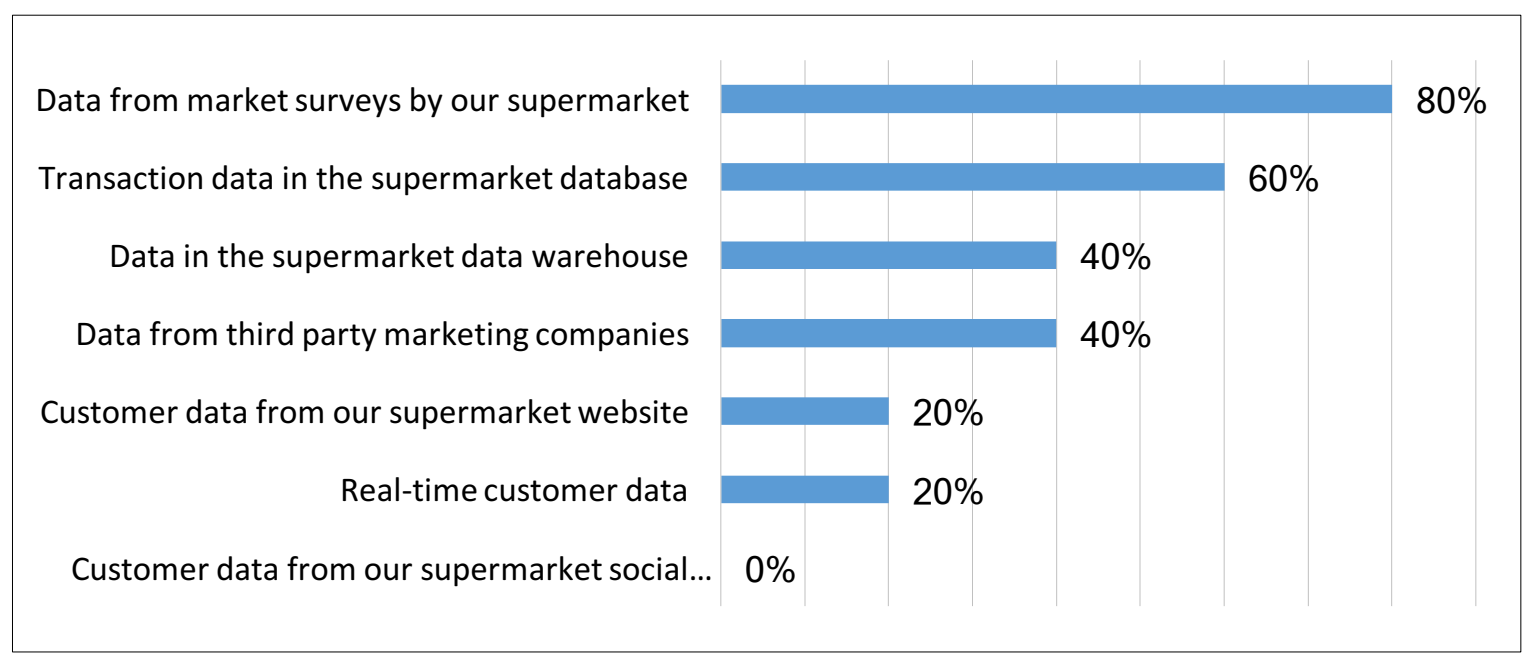

\section{Source: Primary data (2017)}

The results show that large supermarkets in Nairobi still largely prefer traditional sources of data. These sources have limitations in terms of the number of variables that can be obtained in addition to their inability to reflect the constantly changing market dynamics that can be captured through BI technology in real-time or near real time or with other levels of frequency but with less effort. Data from supermarket website logs can for instance reveal the web pages more frequently visited to enable strategic placement of advertised products, or to optimize online customer experience. This data can be used to restructure a website for ease of navigation by customers.

\section{BI technology for data analysis mainly used for market segmentation.}

The study set out to establish the particular components of BI technology the target supermarkets used more. The results presented in Figure 2 show that 60 percent of the supermarkets surveyed chose Market Basket Analysis. OLAP and Sentiment Analysis came second with 20 percent of the supermarkets reporting using them as the main BI for segmentation. The chance to identify any other BI technology not provided in the list yielded the response "Big Data", which essentially is another name for BI technology. 
Figure 2: BI technology for data analysis mainly used for market segmentation

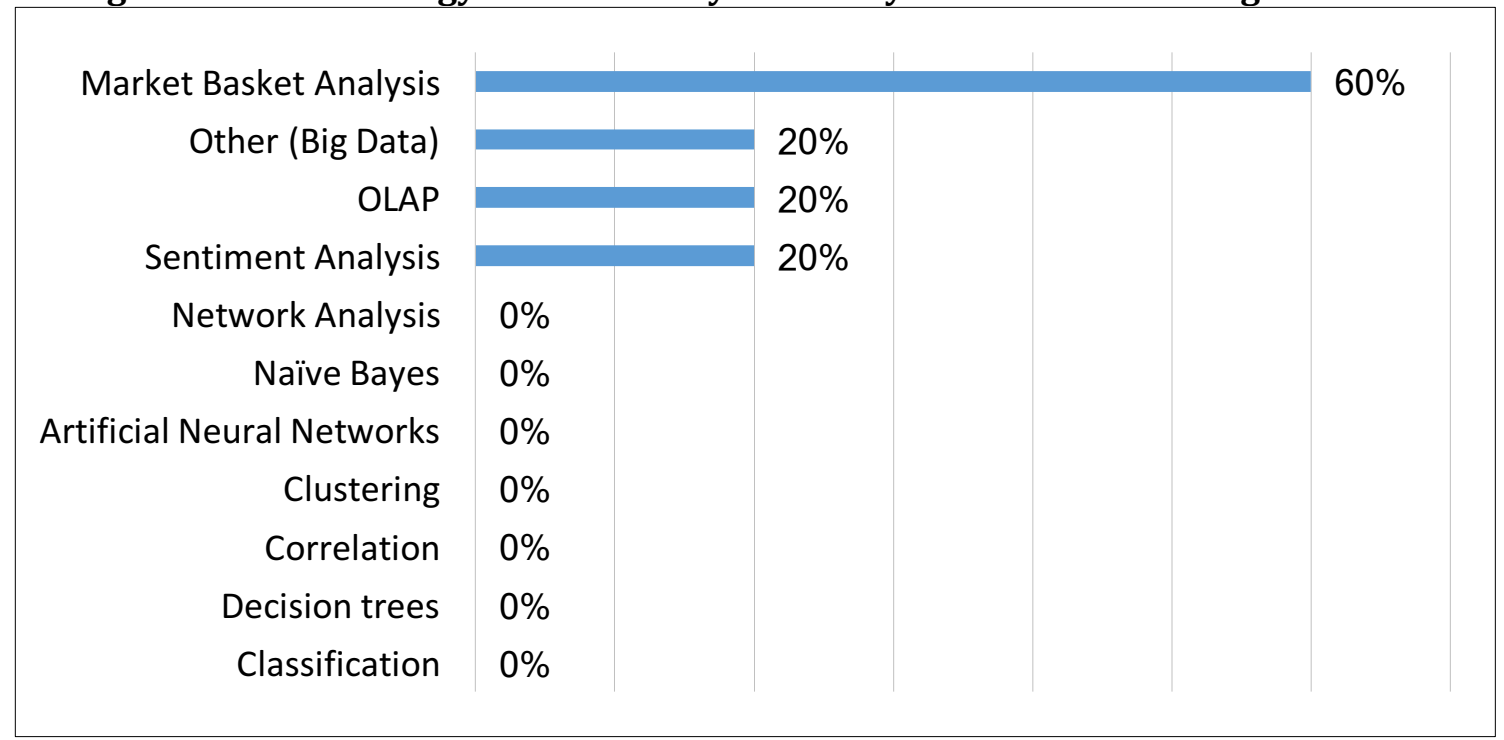

Source: Primary data (2017)

All other components such as clustering, Artificial Neural Networks (ANN) and Decision Trees returned no response, implying the surveyed supermarkets did not use them. Their not being the main BI technology for segmentation suggests that large supermarkets were not placing themselves at the cutting edge of retail BI technology for segmentation. Whereas the most popular-Market Basket Analysis-is used to identify other items a customer could buy on the basis of what other similar customers are buying, classification can be used to segment based on loyalty and customer value, while clustering can be used for behavioral, attitudinal and need segmentation, in addition to demographics (Fotaki, et al, n.d.)Two promotional methods used more than other methods

The study also sought to investigate promotional tactics employed by the participating supermarkets. Specifically, the respondents were required to mention two most frequently used methods. The data presented in Figure 3 show that social media emerged as the most favourite, chosen by 80 percent of the respondents. This was followed by newspapers at 60 percent while the supermarket website came third with 40 percent of the respondents choosing it.

Figure 3: Two promotional methods used more of than the other methods

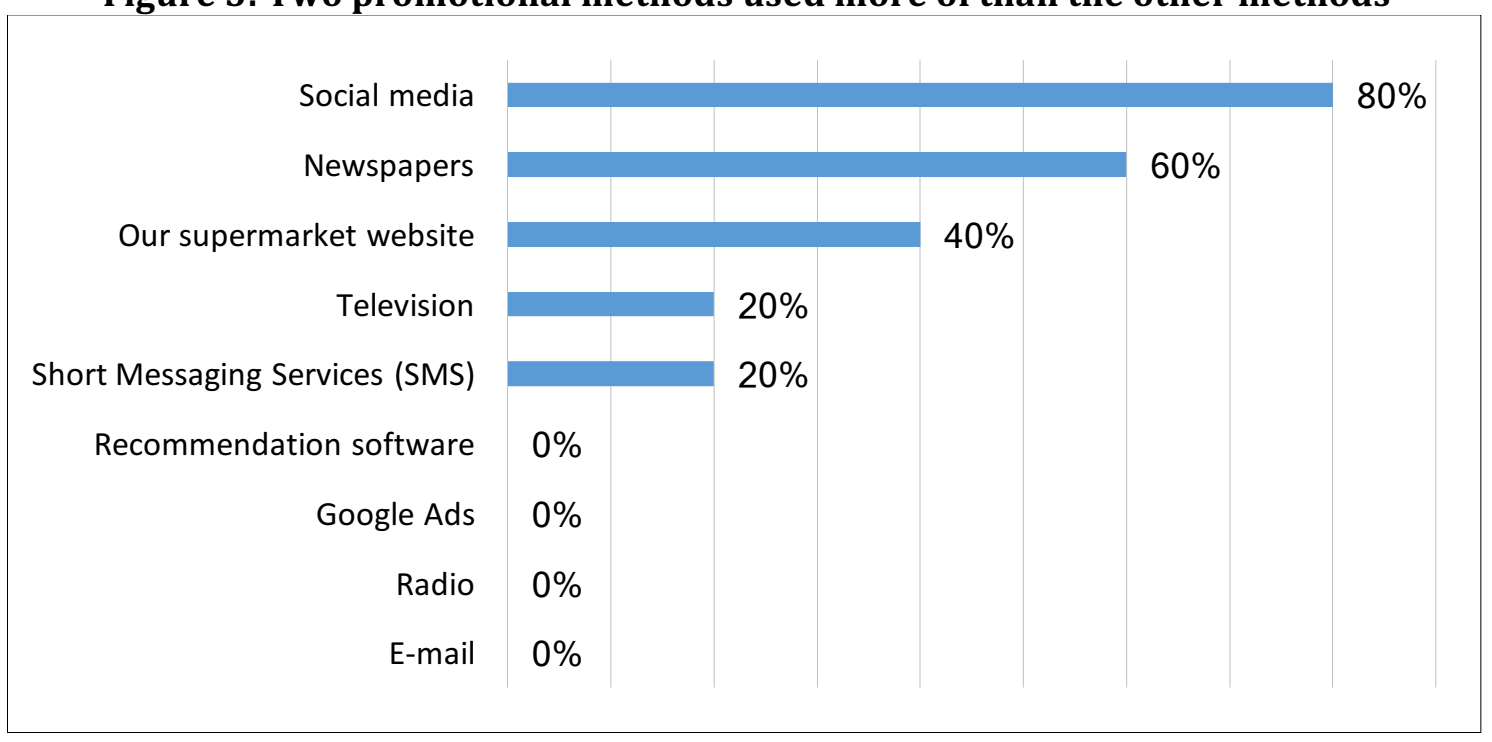

Source: Primary data (2017) 
E-mail, Google Ads and recommendation software did not feature in any of the supermarkets' list as being the best preferred two, signaling lack of appreciation of their potential, such as recommendation software that can account for up to 30 percent increase in sales

\section{Database marketing and segmentation}

The research sought to establish the respondents' views regarding the level of effectiveness of various aspects of BI technology. The pertinent results are presented in 4.1 The findings, detailed in Table 4, show that 50 percent indicated that they strongly agreed while 25 percent agreed somewhat. Secondly, the respondents were asked whether technology for market segmentation had helped achieve marketing strategy objectives, to which 75 percent of the respondents agreed strongly as 25 percent agreed somewhat.

Table 1.1: Effectiveness of BI technology for segmentation

\begin{tabular}{|c|c|c|c|c|c|}
\hline & 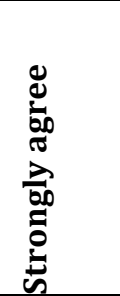 & 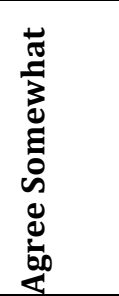 & 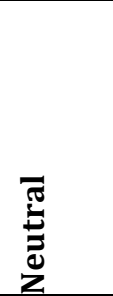 & 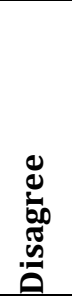 & 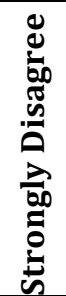 \\
\hline $\begin{array}{l}\text { Data warehousing techniques for } \\
\text { customer segmentation are effective }\end{array}$ & $50 \%$ & $25 \%$ & $25 \%$ & $0 \%$ & $0 \%$ \\
\hline Frequency & 2 & 1 & 1 & 0 & 0 \\
\hline $\begin{array}{l}\text { BI technology for market segmentation } \\
\text { has helped achieve marketing strategy } \\
\text { objectives }\end{array}$ & $75 \%$ & $25 \%$ & $0 \%$ & $0 \%$ & $0 \%$ \\
\hline Frequency & 3 & 1 & 0 & 0 & 0 \\
\hline $\begin{array}{l}\text { Database marketing (micro-targeting) has } \\
\text { made customers buy promoted items }\end{array}$ & $50 \%$ & $50 \%$ & $0 \%$ & $0 \%$ & $0 \%$ \\
\hline Frequency & 2 & 2 & 0 & 0 & 0 \\
\hline Mean & 2.333 & 1.333 & 0.333 & $\mathbf{0}$ & $\mathbf{0}$ \\
\hline Standard deviation & 0.577 & 0.577 & 0.577 & 0 & 0 \\
\hline
\end{tabular}

Source: Primary data (2017)

On the question of whether database marketing had resulted in customers buying promoted items, 50 percent agreed strongly with a similar number saying they agreed somewhat. With a mean of 2.33, therefore, it can be concluded that the respondents strongly agreed that the particular aspects of BI technology used for market segmentation are effective.

\section{Importance of loyalty card program for marketing strategy}

The study sought to establish the level of importance accorded to loyalty card programs by participating supermarkets to six aspects of business. Table 4.2 shows that, overally, at a mean of 1.83333, the general view was found to be that loyalty cards are considered to be highly important as this rating was represented by the numeral 5. Kahalekar \& Patil (2016) note that BI technology can give insight into what products are often bought together and in what quantities; which brand is preferred over others; and prediction of which products are more likely to be bought at a given time, which functions can be facilitated by the loyalty card program. 
Table 4.2 : Rating of importance of loyalty card program

\begin{tabular}{|c|c|c|c|c|c|}
\hline & 5 & 4 & 3 & 2 & 1 \\
\hline $\begin{array}{l}\text { To ensure our customers do not go to our } \\
\text { competitors }\end{array}$ & $50 \%$ & $50 \%$ & $0 \%$ & $0 \%$ & $0 \%$ \\
\hline $\begin{array}{ll}\text { Frequency }\end{array}$ & 2 & 2 & 0 & 0 & 0 \\
\hline To reward customers based on their purchase & $80 \%$ & $20 \%$ & $0 \%$ & $0 \%$ & $0 \%$ \\
\hline Frequency & 4 & 1 & 0 & 0 & 0 \\
\hline To identify other products a customer could buy & $50 \%$ & $0 \%$ & $25 \%$ & $25 \%$ & $0 \%$ \\
\hline Frequency & 2 & 0 & 1 & 1 & 0 \\
\hline To segment customers & $50 \%$ & $0 \%$ & $0 \%$ & $50 \%$ & $0 \%$ \\
\hline Frequency & 2 & 0 & 0 & 2 & 0 \\
\hline $\begin{array}{l}\text { To customize marketing based on customer } \\
\text { profile }\end{array}$ & 0 & $25 \%$ & $75 \%$ & $0 \%$ & $0 \%$ \\
\hline Frequency & 0 & 1 & 3 & 0 & 0 \\
\hline To know if a customer responded to a promotion & $25 \%$ & $0 \%$ & $75 \%$ & $0 \%$ & $0 \%$ \\
\hline Frequency & 1 & 0 & 3 & 0 & 0 \\
\hline Mean & 1.8333 & 0.6667 & 1.1667 & 0.5 & $\mathbf{0}$ \\
\hline Standard Deviation & 1.3292 & 0.8165 & 1.4720 & 0.8367 & $\mathbf{0}$ \\
\hline
\end{tabular}

Source: Primary data (2017)

The results indicate 80 percent of the respondents considered loyalty cards to be very important in rewarding customers based on their purchase while 50 percent considered it to be highly important in ensuring customers do not go to competitors, to identify other products a customer could buy, and to segment customers. However, 75 percent of the respondents gave a rating of 3 to two uses of the loyalty card, namely, to customize marketing based on customer profile and to know if a customer responded to a promotion.

\section{Effectiveness of database marketing in conversion}

The researcher also probed the respondents' perception of the effectiveness of database marketing (micro-targeting marketing) in converting a customer, that is, making a customer purchase the promoted item. The findings presented in graphical form in Figure 4 show that 50 percent reported that they agree somewhat, with a similar percentage reporting that they were neutral. Only 25 percent reported to strongly agree.

Figure 4: Effectiveness of database marketing in conversion

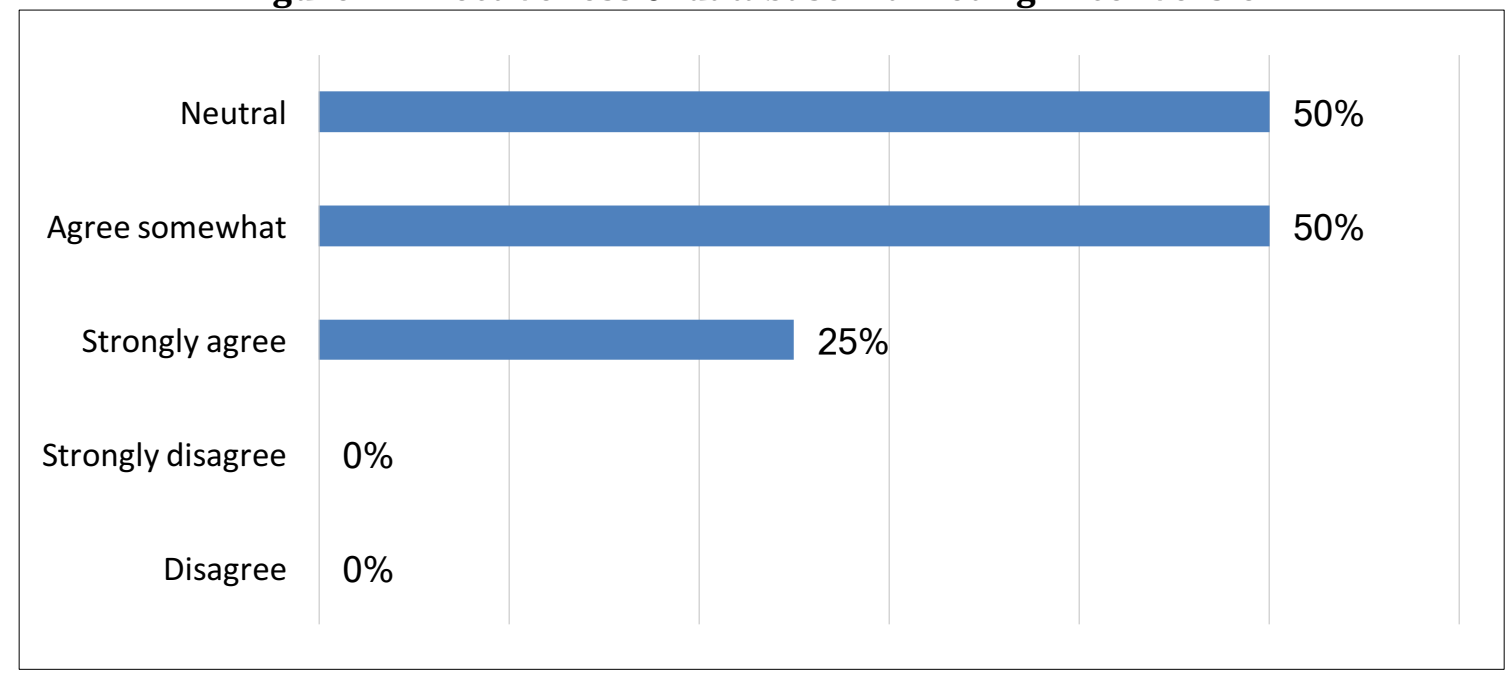

Source: Primary data (2017) 
These responses, in general reflecting dissatisfaction with direct marketing, should be assessed in the context of responses to the question regarding which BI technologies are mainly used by supermarkets for segmentation (see Figure 2). That is, if full advantage is taken of BI segmentation techniques capable of analyzing a wider range of variables such as attitudinal, behavioral, demographic among others, then segmentation would be more accurate and yield better conversion rates.

\section{Business Intelligence Technology and Product Development}

The research sought to establish the extent to which supermarkets in the survey use particular sources of information to inform the introduction of a new product or service. The findings are summarized in Table 4.3 showing that transaction data in the supermarket database was used by 80 percent of the supermarkets who said they did so to a very great extent, underlining the popularity of this source of information. Another 20 percent reported using this source to a great extent. 40 percent of the respondents reported that, to a very great extent, they used market surveys by internal marketing staff to introduce new products; and another 40 percent did the same to a moderate extent. Only 20 percent admitted to using internal staff to conduct market surveys. That only 20 percent used online data sources-supermarket websites and social media-to get ideas for new products to a very great extent, in contrast to 80 percent that used supermarket transaction database, adds to earlier conclusion that large supermarkets in Nairobi were experiencing a lag in terms of adoption of state-of-the-art retail data analytics.

Table 4.3: The extent of using data sources to introduce a new product/service

\begin{tabular}{|c|c|c|c|c|c|}
\hline & 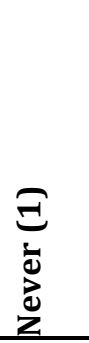 & 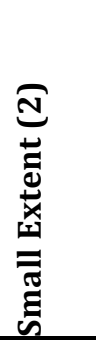 & 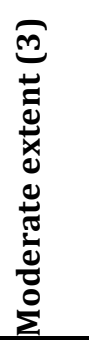 & 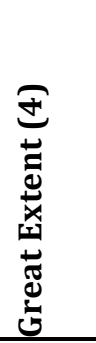 & 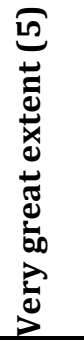 \\
\hline Market surveys conducted by our marketing staff & $0 \%$ & $20 \%$ & $40 \%$ & $0 \%$ & $40 \%$ \\
\hline Frequency & 0 & 1 & 2 & 0 & 2 \\
\hline Third party marketing companies & $0 \%$ & $40 \%$ & $20 \%$ & $20 \%$ & $0 \%$ \\
\hline Frequency & 0 & 2 & 1 & 1 & 0 \\
\hline Transaction data in the supermarket database & $0 \%$ & $0 \%$ & $0 \%$ & $20 \%$ & $80 \%$ \\
\hline Frequency & 0 & 0 & 0 & 1 & 4 \\
\hline Data in the supermarket data warehouse & $20 \%$ & $0 \%$ & $20 \%$ & $20 \%$ & $40 \%$ \\
\hline Frequency & 1 & 0 & 1 & 1 & 2 \\
\hline Customer data from our supermarket website & $20 \%$ & $40 \%$ & $0 \%$ & $20 \%$ & $20 \%$ \\
\hline Frequency & 1 & 2 & 0 & 1 & 1 \\
\hline Customer data from company social media & $0 \%$ & $0 \%$ & $40 \%$ & $40 \%$ & $20 \%$ \\
\hline Frequency & 0 & 0 & 2 & 2 & 1 \\
\hline
\end{tabular}

Source: Primary data (2017) 
When analyzed with BI technology like Artificial Neural Networks, for example, data are capable of yielding far more accurate predictions of what a customer needs and is ready to buy at a given point in time. In contrast to all other sources, only customer data from supermarket website and data in the supermarket data warehouse posted a 20 percent frequency of never, implying supermarkets did not employ any of these two sources of information for identifying opportunity to introduce new products.

\section{Social media and product development}

The researcher sought to establish the management's view regarding social media analytics tools (social media BI components) were considered as important to marketing strategy. The results are presented in Table 4.4. The findings are tabulated in Table 7 showing that 60 percent agreed strongly while 20 percent agreed somewhat and another twenty percent remained neutral. Regarding the question on whether Network Analysis component of BI technology is key to understanding their supermarket customers, 60 percent strongly agreed as contrasted with 20 percent who agreed somewhat and another twenty percent who remained neutral. This indicates that the majority of supermarkets appreciate the importance of social media BI technology in marketing strategy.

The study also sought to assess whether new products the supermarkets introduced based on analysis of contents of social media and comment sections of their websites sold successfully. Table 7 shows only 20 percent agreed strongly while 60 percent agreed somewhat. Another 20 percent remained neutral.

Table 4.4 : Perception of effectiveness of BI technology

\begin{tabular}{|c|c|c|c|c|c|c|}
\hline & & 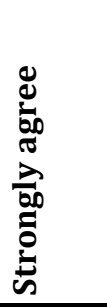 & 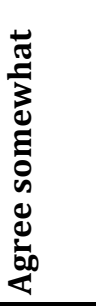 & 莺 & 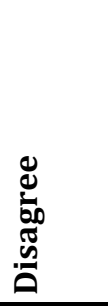 & 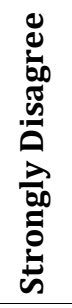 \\
\hline \multirow{2}{*}{$\begin{array}{l}\text { Sentiment analysis component of } \\
\text { Business Intelligence Technology is } \\
\text { key to our marketing strategy }\end{array}$} & Percentage & $60 \%$ & $20 \%$ & $20 \%$ & $0 \%$ & $0 \%$ \\
\hline & Observations & 3 & 1 & 1 & 0 & 0 \\
\hline \multirow{3}{*}{$\begin{array}{l}\text { Network analysis component of } \\
\text { Business Intelligence Technology is } \\
\text { key in understanding our customers }\end{array}$} & Percentage & $60 \%$ & $20 \%$ & $20 \%$ & $0 \%$ & $0 \%$ \\
\hline & Observations & 3 & 1 & 1 & 0 & 0 \\
\hline & Mean & 3 & 1 & 1 & $\mathbf{0}$ & $\mathbf{0}$ \\
\hline $\begin{array}{l}\text { New products our supermarket has } \\
\text { introduced based on analysis of } \\
\text { social media sites and comment } \\
\text { sections of our website have sold } \\
\text { successfully }\end{array}$ & Observations & $20 \%$ & $60 \%$ & $20 \%$ & $0 \%$ & $0 \%$ \\
\hline
\end{tabular}

Source: Primary data (2017)

From the results, 60 percent agree strongly that Network Analysis and Sentiment Analysis are key to marketing strategy, yet when it comes to the question of how well the products 
introduced as a result of these techniques are selling, the perception shifts, with 60 percent agreeing somewhat and only 20 percent of the respondents agreeing strongly. It could be that the BI techniques are not deployed optimally as stand-alone tools, or are not being used with other more effective methods.

\section{Monitoring social media conversation}

The study set to establish the reasons supermarkets had for monitoring social media conversation. The result in Figure 5 show three choices tying at 80 percent. These were: to promote products online, to influence customer views about the supermarkets, and to understand the supermarkets' online reputation. To manage online reputation was reported by 60 percent of the respondents as the rationale for monitoring social media. This was in contrast to 40 percent for whom identifying opportunities to introduce new products informed the decision to monitor social media conversation.

Figure 5: Reasons for monitoring social media conversation

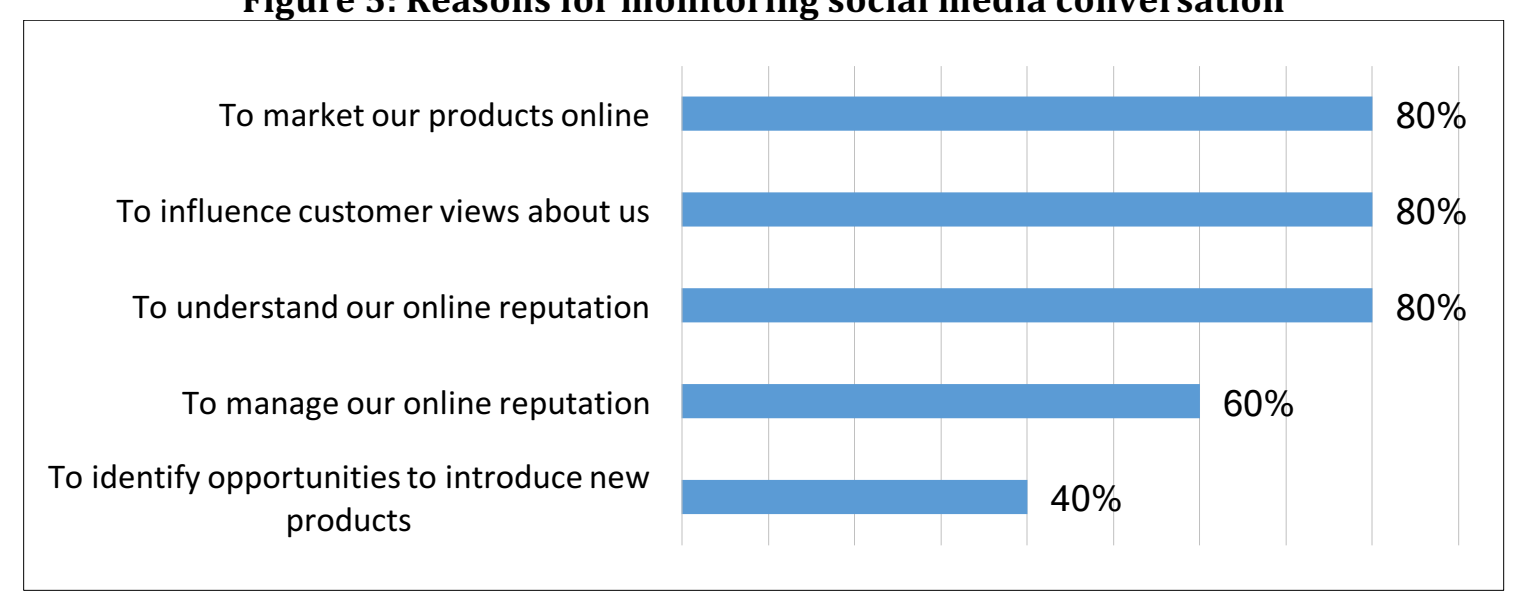

Source: Primary data (2017)

This shows a low rate of usage of social media analytics to spot opportunities to introduce new products. The social media was still largely being used for traditional roles of product promotion and online reputation management rather than as an additional source of rich, objective data that can be fed into the data warehouse to inform on trends that supermarkets can leverage to introduce new products.

\section{Initiative for online shopping}

Figure 6: Initiative for online shopping

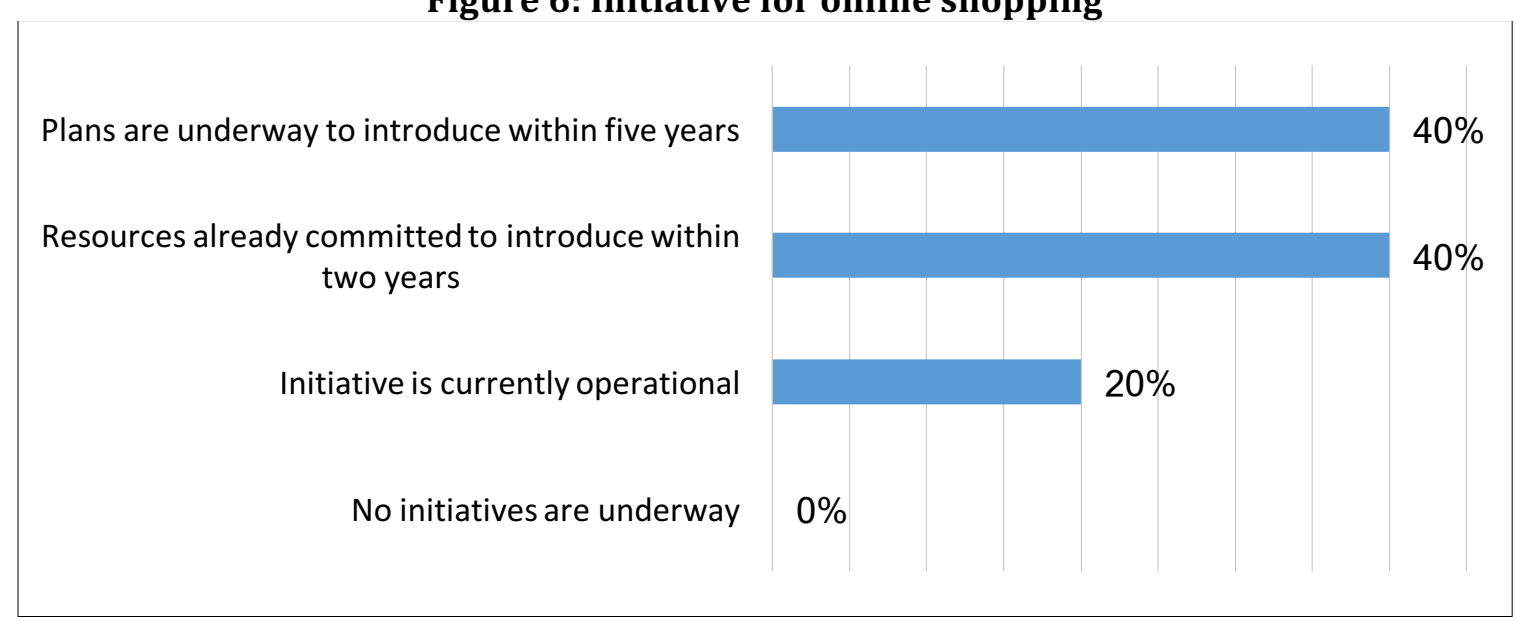

Source: Primary data (2017) 
Figure 6 presents the findings on the question of whether the supermarkets had any initiative for establishing online shopping. 20 percent of the respondents answered in the affirmative. 40 percent reported that resources had already been committed to venture into e-commerce while a similar proportion reported that plans were underway to introduce it within five years.

None of the surveyed supermarkets lacked an initiative for online selling of some sort. Online shopping can provide an additional source of behavioral and attitudinal data that can support individualized, micro-targeting, database marketing (Sudhakar et al. n.d.). This data can be subjected to analysis using BI technology to yield insights that can be leveraged by the supermarkets to improve loyalty, cross-selling and new product development.

\section{BI technology and customer information}

The surveyed supermarkets were also asked to rate, on a scale of 1 to 5 , the extent to which they used BI technology to identify specific purchase-related data. Table 8 show that 50 and 40 percent respectively reported never (1) using BI technology to collect and analyze data related to family life cycle and buyer of product A will also buy product B (cross-sell opportunity). On the other extreme end of 5-very great extent - the most frequent choice was Buyer of product A will also buy product $B$, chosen by 40 percent of respondents thus having a situation where cross-sell data was equally distributed at both ends. The collected data shows that predictive data on a person's life cycle is not collected by supermarkets to enable them to predict items likely to be bought at a particular point in the lifecycle such as marrying and buying related items. This conclusion is informed by 50 percent who reported never collecting data about family lifecycle while another 25 percent only collected such data to a small extent.

The mean of 1.333 for never being the highest implies that in general the surveyed supermarkets largely do not use BI technology to identify customer information of any type. This is supported by the lowest means of 0.333 being for very great extent and great extent, whose implication is that only a very small fraction of the supermarkets use BI technologies to identify customer information of any type.

Table 4.6: The extent of using BI technology to get information about customers

\begin{tabular}{|c|c|c|c|c|c|c|}
\hline & & 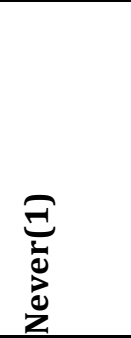 & 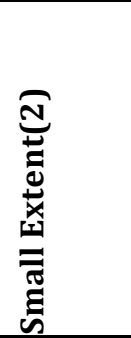 & 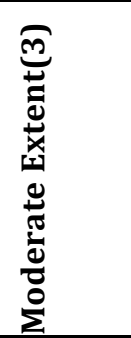 & 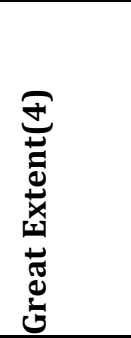 & 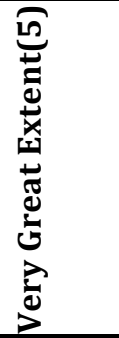 \\
\hline \multirow[t]{2}{*}{ Customer product preference } & Percentage & $25 \%$ & $25 \%$ & $50 \%$ & $0 \%$ & $0 \%$ \\
\hline & Observations & 1 & 1 & 2 & 0 & 0 \\
\hline \multirow[t]{2}{*}{ Changing customer tastes } & Percentage & $20 \%$ & $20 \%$ & $20 \%$ & $20 \%$ & $20 \%$ \\
\hline & Observations & 1 & 1 & 1 & 1 & 1 \\
\hline \multirow[t]{2}{*}{ Buyer of product A will buy product B } & Percentage & $40 \%$ & $0 \%$ & $20 \%$ & $0 \%$ & $40 \%$ \\
\hline & Observations & 2 & 0 & 1 & 0 & 2 \\
\hline \multirow[t]{2}{*}{ Likelihood to change loyalty to rivals } & Percentage & $20 \%$ & $20 \%$ & $40 \%$ & $0 \%$ & $20 \%$ \\
\hline & Observations & 1 & 1 & 2 & 0 & 1 \\
\hline \multirow[t]{2}{*}{ Product Seasonality } & Percentage & $25 \%$ & $0 \%$ & $25 \%$ & $50 \%$ & $0 \%$ \\
\hline & Observations & 1 & 0 & 1 & 2 & 0 \\
\hline \multirow[t]{3}{*}{ Family Life Cycle } & Percentage & $50 \%$ & $25 \%$ & $0 \%$ & $25 \%$ & $0 \%$ \\
\hline & Observations & 2 & 1 & 0 & 1 & 0 \\
\hline & Mean & 1.333 & 0.667 & 1.167 & 0.333 & 0.333 \\
\hline
\end{tabular}

Source: Primary data (2017) 


\section{Products introduced based on BI technology analysis of online data}

The study also set out to establish if the supermarkets, based on BI technology, had introduced new products. Majority of the supermarkets-80 percent-reported to have done so. Those responding in the affirmative pointed out the products thus introduced, namely, fresh pastry, hot deli, a shopping mobile app, private labels and a butchery. The category of the products vary but foods dominate.

\section{BI Technology and Market Penetration}

\section{Proportion of supermarkets maintaining social media}

A question was also asked to know which social media application was used by the supermarkets. The findings shown in Figure 7, show that Twitter and Facebook were the social media sites found to be maintained by all the supermarkets surveyed, hence the100 percent for both applications. Sentiment and Network Analyses component of BI are widely applied on both applications. In contrast, only 40 percent of the supermarkets participating in the study reported having WhatsApp and Instagram accounts. Google+ was not used by any of the respondent supermarkets.

Figure 7: Social media site(s) maintained by supermarkets

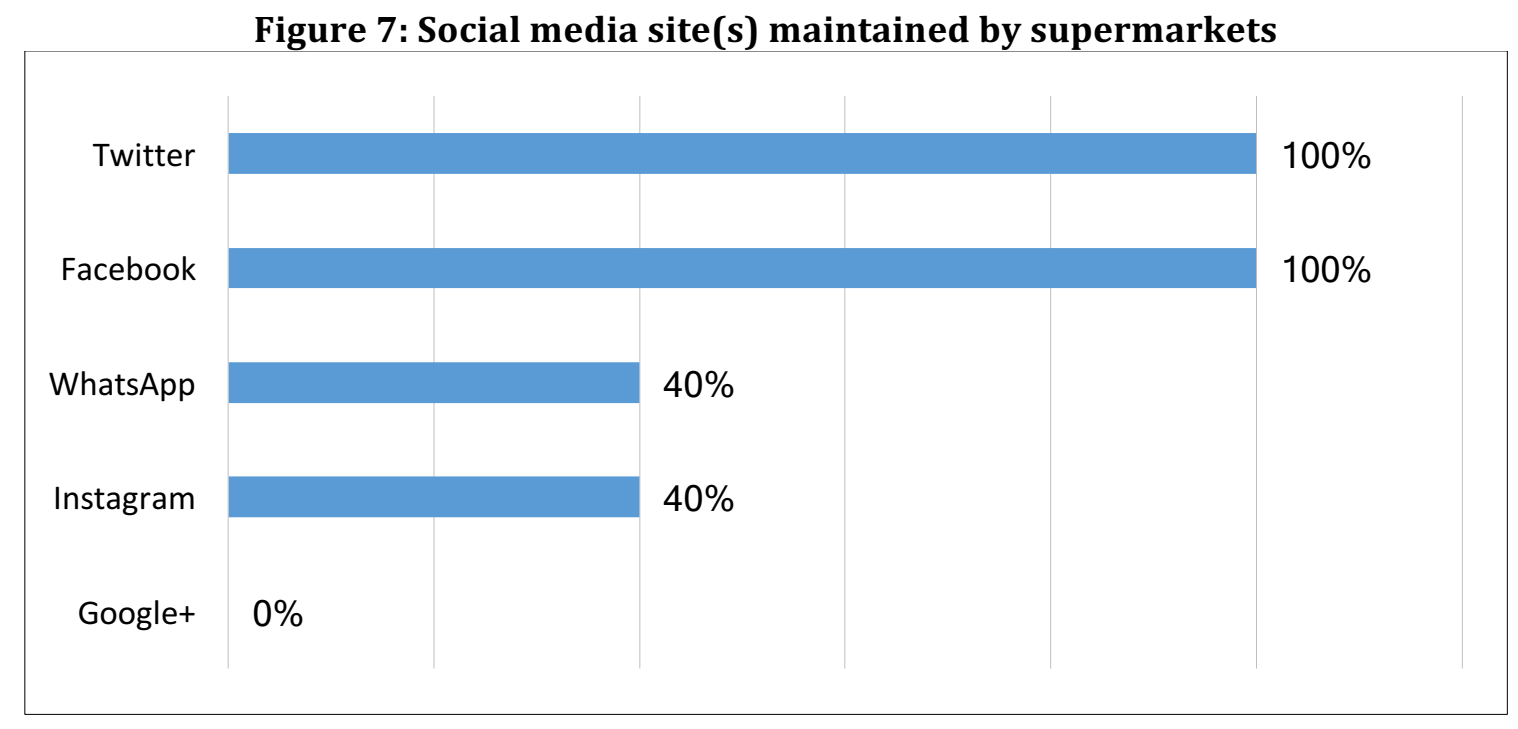

Source: Primary data (2017)

\section{Analytics technologies used to analyze official social media sites}

The study also wanted to establish which social media analytics supermarkets used. The findings in Figure 8 below show that at 40\% each, Sentiment Analysis and Network Analysis were used more than other technologies for analyzing social media content. Sentiment Analysis is used to gauge social media content for negative or positive feelings towards an entity, which could be a supermarket; while Network Analysis is deployed in measuring the extent and quality of social connectedness of a subject.

$20 \%$ of the respondents used none of the social media analytics while Clustering, Classification Rules, and Artificial Neural Networks were used by none of the respondents in analyzing social media content. A provision for other analytics technologies used but not in the list elicited one technology, namely, Google Analytics, from 17\% of the respondents. Google Analytics is used to capture traffic to a website. 
Figure 8: BI technologies used to analyze official social media sites

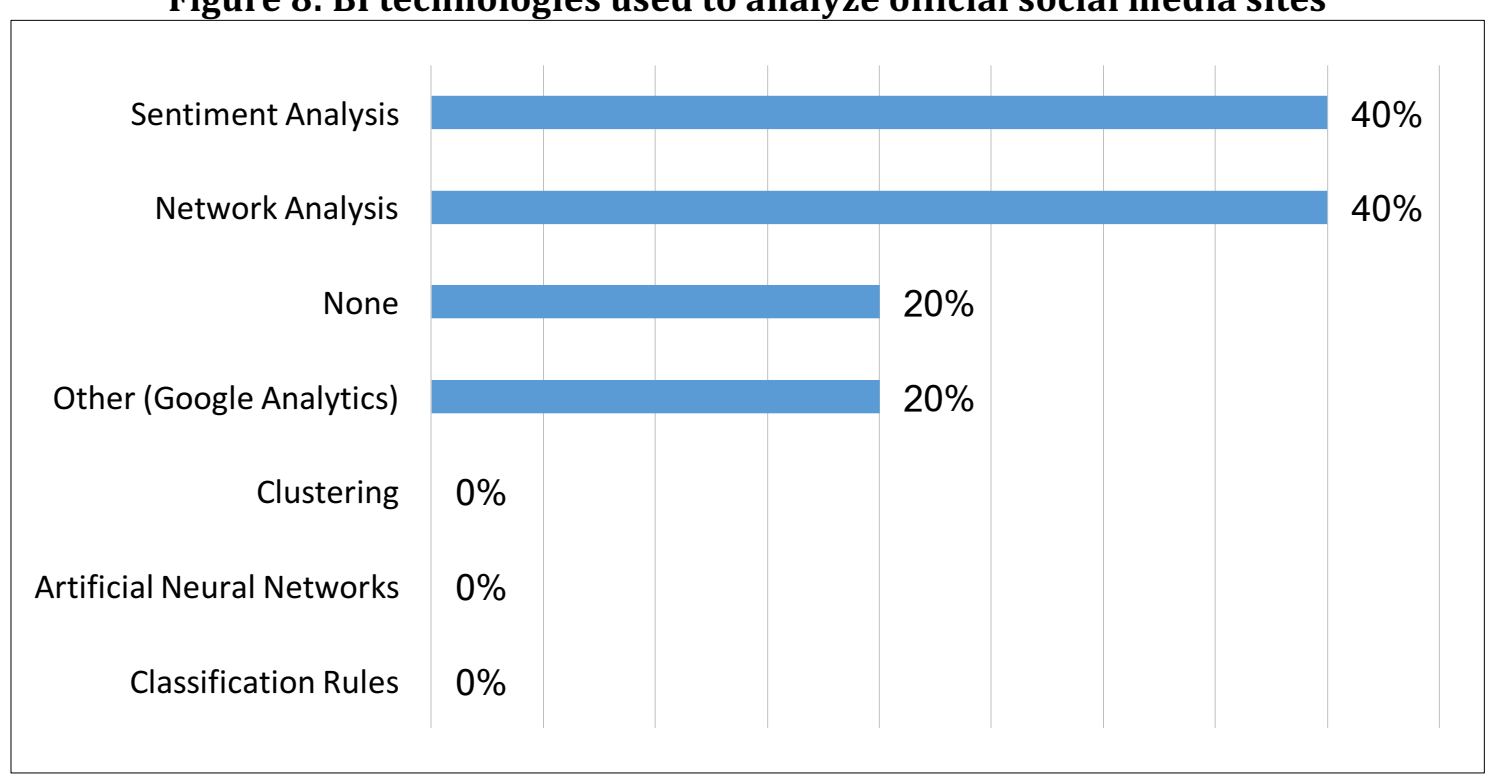

Source: Primary data (2017)

\section{Purpose for web and social media analysis and monitoring}

The researcher also probed the supermarkets regarding the reasons for monitoring and analyzing social media activity. Figure 9 presents the findings that two equally major reasons for conducting web and social media analysis and monitoring were to handle customer complaints and to know what customers are saying about the respective supermarkets. All respondents chose these two reasons at 100 percent. These were followed by getting feedback about products at 80 percent. Keeping customers engaged with the brand, advertising products and attracting new customers were each chosen by 60 percent of the respondents.

The reason least chosen by the respondents as the purpose for monitoring and analyzing supermarket websites and social media was collecting data to inform marketing strategy. Only 20 percent of the respondents chose this option. This low use of social media and website data to inform marketing strategy is indicative of a lack of comprehensive digital strategy. Supermarkets were not taking advantage of the ability to reach customers and potential ones virtually everywhere. They have not adapted their marketing to the digital age, but have only transferred the old methods to a new platform, hence 100 percent who use social media to handle complaints and manage reputation.

Figure 9: Reasons for monitoring and analyzing activity on website and social media

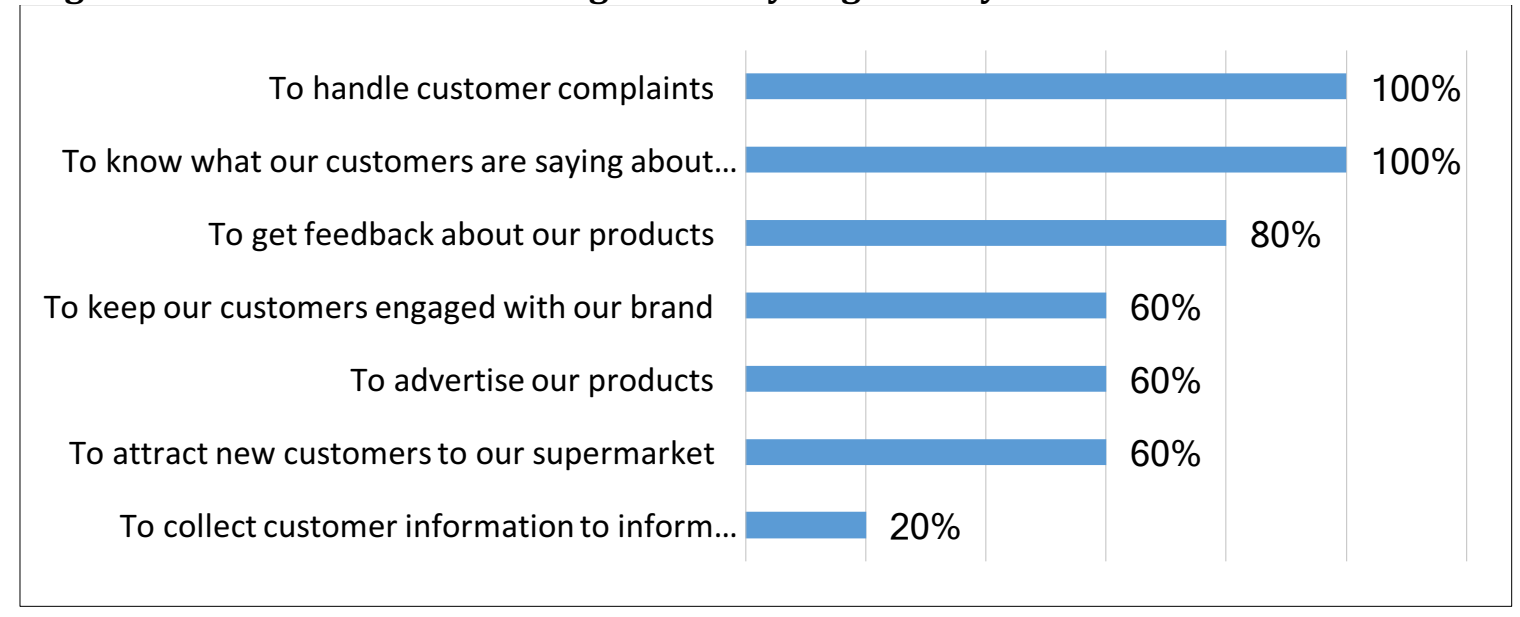

Source: Primary data (2017) 


\section{Social media and market segmentation}

Table 4.7. Effectiveness of BI technology in market penetration

\begin{tabular}{|c|c|c|c|c|c|}
\hline & 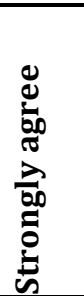 & 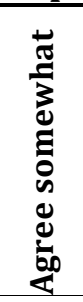 & $\underset{z}{\overline{3}}$ & 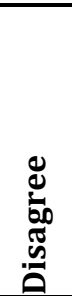 & 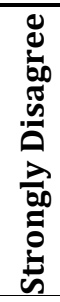 \\
\hline $\begin{array}{l}\text { The use of predictive analytics to inform market } \\
\text { penetration strategies has seen our supermarket gain } \\
\text { more customers. }\end{array}$ & $0 \%$ & $60 \%$ & $40 \%$ & $0 \%$ & $0 \%$ \\
\hline $\begin{array}{l}\text { The use of social media network analysis for purposes } \\
\text { of product promotion has resulted in more customers } \\
\text { buying our products }\end{array}$ & $40 \%$ & $20 \%$ & $40 \%$ & $0 \%$ & $0 \%$ \\
\hline
\end{tabular}

Source: Primary data (2017)

The study also aimed at finding out whether the use of predictive analytics to inform market penetration strategies had resulted in increase in the number of customers. Table 9 shows that none of the respondents agreed strongly; but 60 percent agreed somewhat while another 40 percent remained neutral. Regarding whether the use of social media network analysis to promote products resulted in more customers buying products, 40 percent agreed strongly, 20 percent agreed somewhat, while 40 percent remained neutral. It therefore appears that supermarkets have more confidence in social media network analysis for market penetration than in other predictive analytics. However, with 40 percent remaining neutral for both predictive analytics and social media network analysis, the implication could be either lack of usage of the two or an unsatisfactory performance, which could result from a number of factors.

A follow-up question required respondents to rate the level of customer uptake of offers based on sentiment analysis of social media content. The study found that $100 \%$ of the surveyed supermarkets rated the level of uptake of offers by customers based on sentiment analysis to be Medium. None chose either High or Low, implying that the success rate of sentiment analysis of social media was moderate.

\section{Factors affecting effectiveness of database marketing}

Table 4.8 Effectiveness of database marketing

\begin{tabular}{llllll}
\hline & & & & & \\
& & & & & \\
\end{tabular}

Source: Primary data (2017) 
The study also set out to probe supermarket practices relating to database marketing. The results presented in Table 4.8 show that only 20 percent of supermarkets surveyed sent microtargeting promotional messages often while 60 percent sent sometimes. None admitted to sending always while 20 percent rarely sent such promotional messages. That a mere 20 percent of supermarkets engaged in database marketing is a signal that a very low usage of cross-selling potential of BI technology was in place. The question regarding how often customers directly targeted based on their purchase history responded positively to promotions, yielded a response of 40 percent often and 60 percent sometimes.

\section{Logistic Regression}

The study made use of logistic regression analysis to establish the relationship between various variables, namely, the predictor BI technology variable and the perceived outcome, that is, whether the supermarkets deployed the marketing strategies dependent on those technologies. The study employed both binary logistic regression and multinomial depending on whether the dependent variable had two or more values.

\section{Influence of data warehousing for segmentation on database marketing}

Binary logistic regression was used to test whether how often a supermarket targets customers directly using database marketing depended on whether it used data warehousing for segmentation. The Likelihood Ratio Tests below in Table 4.8, showing a significance of 0.035 (less than the threshold of 0.05), supports the hypothesis.

Table 2: Likelihood Ratio Tests

\begin{tabular}{|l|c|c|c|c|}
\hline \multirow{2}{*}{ Effect } & $\begin{array}{c}\text { Model Fitting } \\
\text { Criteria }\end{array}$ & \multicolumn{3}{|c|}{ Likelihood Ratio Tests } \\
\cline { 2 - 5 } & $\begin{array}{c}\text {-2 Log Likelihood of } \\
\text { Reduced Model }\end{array}$ & Chi-Square & df & Sig. \\
\hline Intercept & $1.622^{\mathrm{a}}$ & .000 & 0 &. \\
S.Weusedatawarehouseforsegmentation & 8.352 & 6.730 & 2 & .035 \\
\hline
\end{tabular}

Source: Primary data (2017)

This finding is confirmed by the Nagelkerke parameter of Pseudo R-Square in Table 4.9 predicting that 84.2 percent of the cases where data warehousing is used sometimes or often for segmentation, customers will be directly targeted.

Table 4.9: Pseudo R-Square

\begin{tabular}{|l|l|}
\hline Cox and Snell & .740 \\
Nagelkerke & .842 \\
McFadden & .638 \\
\hline
\end{tabular}

\section{Source: Primary data (2017)}

Table 4.10 for Classification also predicts that where data warehousing is used often and sometimes for segmentation, customers will be directly targeted in 40 and 60 percent of the cases respectively, while where data warehousing is never used for segmentation, microtargeting will not be used. This attests to the importance of using a variety of BI techniques.

Table 4.10 Classification

\begin{tabular}{|l|c|c|c|c|}
\hline \multirow{2}{*}{ Observed } & \multicolumn{3}{|c|}{ Predicted } \\
\cline { 2 - 5 } & Never & Often & Sometimes & Percent Correct \\
\hline Never & 0 & 0 & 1 & $.0 \%$ \\
Often & 0 & 2 & 0 & $100.0 \%$ \\
Sometimes & 0 & 0 & 2 & $100.0 \%$ \\
Overall Percentage & $.0 \%$ & $40.0 \%$ & $60.0 \%$ & $80.0 \%$ \\
\hline
\end{tabular}

Source: Primary data (2017) 
The influence of extent of using social media customer data for new product on monitoring and analyzing online activity to get data for marketing strategy

The study also used Logistic Regression Analysis to establish the relationship between the extent of using social media customer data to introduce new products on the one hand, and monitoring and analyzing online activity to get data for marketing strategy. The relationship was not significant since, at 0.215 as shown in Table 4.11, it was above the threshold of 0.05 .

Table 4.11 Variables in the Equation

\begin{tabular}{|ll|c|c|c|c|c|c|}
\hline & & B & S.E. & Wald & df & Sig. & Exp(B) \\
\hline Step 0 & Constant & -1.386 & 1.118 & 1.537 & 1 & .215 & .250 \\
\hline
\end{tabular}

Source: Primary data (2017)

\section{The influence of Market Basket Analysis and database marketing on the effectiveness of data warehousing for segmentation}

On testing which between sending product promotion messages to customers based on their past purchase history and using Market Basket Analysis for segmentation, relates with data warehousing effectiveness, it was found that micro-targeting-at a significance of 0.36 as shown in Table 4.12-is a better predictor of effectiveness of data warehousing than using Market Basket Analysis for segmentation on its own. This implies that data warehousing is more effective when micro-targeting is used rather than if Market Basket Analysis is done on its own.

Table 4.13 Likelihood Ratio Tests

\begin{tabular}{|l|c|c|c|c|}
\hline & \multicolumn{3}{|c|}{$\begin{array}{l}\text { Model Fitting } \\
\text { Criteria }\end{array}$} & \multicolumn{3}{|c|}{ Likelihood Ratio Tests } \\
\cline { 2 - 5 } Effect & $\begin{array}{l}\text {-2 Log Likelihood } \\
\text { of Reduced Model }\end{array}$ & Chi-Square & df & Sig. \\
\hline $\begin{array}{l}\text { Intercept } \\
\text { Wesendproductpromotionalmessagestocustomersbased }\end{array}$ & $1.386^{\mathrm{a}}$ & .000 & 0 &. \\
ontheirpurchas & 7.978 & 6.592 & 6 & .360 \\
WeuseMBAnalysisforSegmentation & 2.433 & 1.047 & 3 & .790 \\
\hline
\end{tabular}

Source: Primary data (2017)

\section{DISCUSSION OF RESULTS}

The study sought to establish the sources of data the supermarkets used for market segmentation. The findings indicate that with the exception of customer data gleaned from supermarket social media, the supermarkets used all sources provided in the list but to varying degrees. The most used was data from market surveys with 80 percent of the respondents using it. The least used sources were customer data from supermarket websites and real-time customer data each at 20 percent.

The research also set out to establish the BI technologies mainly used for market segmentation by participating supermarkets. The data collected show that Market Basket Analysis is deployed by 60 percent of the surveyed retailers while Sentiment Analysis and OLAP were also each made use of by 20 percent of the respondent supermarkets. It was also established that clustering, correlation, decision trees, Artificial Neutral Networks, Network Analysis and Naïve Bayes were hardly used by the responding supermarkets for market segmentation. The followup question on whether the BI technology used for market segmentation was accurate yielded positive response in affirmation.

Two promotional methods most preferred by the supermarkets emerged to be social media and newspapers. Recommendation software, Google Ads and E-mail appeared not to enjoy support as none of the respondents picked any of them. This is an indication that supermarkets 
have not scaled up to automated BI technologies such as recommendation software, whose example is Google Ads, for individualized promotions.

The study also sought to find out was the extent of effectiveness of particular aspects of BI technology in segmenting a market. These were data warehousing techniques and whether, through database marketing (micro-targeting), their usage had resulted in the supermarket attaining the strategic objectives of marketing. 75 percent agreed that data warehousing techniques were effective in market segmentation and that, additionally, database marketing was also effective. The respondents were also required to rate loyalty cards programs in terms of how important it was to the supermarket in view of particular purposes for which the card was used. These purposes were: to ensure our customers do not go to our competitors, to reward customers based on their purchase, to identify other products a customer could buy, to segment customers, to customize marketing based on customer profile, and to know if a customer responded to a promotion. After computing the scores for various ratings for all the six purposes, the score of five emerged the best with a mean of 1.83 . This implied that the respondents were satisfied with the performance of loyalty card across the functions. However, two functions - to customize marketing based on customer profile and to know if a customer responded to a promotion-received a lower rating of 3 out of 5 in the scale of importance, yet the two constitute a significant role of BI technology in enhancing marketing strategy.

Database marketing is an aspect of marketing strategy supported by BI technology. The study thus sought to know whether the supermarkets in the study effectively implemented it in their business, that is, if its implementation resulted in high conversion rates. Only 25 percent of the respondents agreed strongly, as opposed to another 50 percent who agreed somewhat and a similar number opting for neutrality.

Regarding the sources of information for introduction of new products, the research established that transaction data in the supermarket database was used by 80 percent of the supermarkets who said they did so to a very great extent. 40 percent of the respondents reported to use market surveys by internal marketing staff to a very great extent to introduce new products; and another 40 percent did the same to a moderate extent. In contrast, only 20 percent used online data sources like supermarket websites and social media to get ideas for new products to a very great extent, thus further confirming that large supermarkets in Nairobi have largely not embraced the state-of-the-art retail BI data analytics, which have a higher precision in predicting what customers would like to buy.

On whether Sentiment Analysis and Network Analysis was key to marketing, the respondents strongly agreed with a mean of three; however, the respondents only agreed somewhat when probed regarding whether new products introduced based on analysis of online customer content sold successfully. This points to a disconnect between optimism for BI web technologies and their practical application, that is, that they could be used only for communication with customers but not optimized to identify opportunities for introducing new products. This failure to exploit online sources for ideas on which new products to introduce is consistent with the purposes for which supermarkets monitor social media conversation. This is because monitoring social media for reasons of exploring opportunities to introduce new products was chosen by the least number of supermarkets: 40 percent. This was in contrast to other reasons such as promotions, customer feedback and online reputation, each of which was chosen by 80 percent of the supermarkets as the reason for monitoring and analyzing social media conversation. 
Another finding was that only one of the five surveyed supermarkets had online shopping facility. The rest had plans to introduce it within either two or five years. The implications of this is that those with plans to introduce it in five years' time may not really have such plans and as a result are missing out on fully leveraging BI technology which for retailers can be optimized on an online shopping platform. Online shopping provides a vast array of diverse customer data that can be collected and analyzed in real time to provide far more accurate and highly granular information about customer behavior-both online and offline-attitudes, location, needs, class, trends, and a wide variety of other valuable attributes.

The study further established that the surveyed supermarkets to a very small extent used BI technology to identify customer information. With a mean of 1.33 being the highest for the option of never using such technology, and a mean of 0.33 for very great extent and great extent being the lowest, it was clear that supermarkets had not yet to a significant extent adopted BI technology for analysis of customer-related data. This explains why when asked to enumerate new products the retailers have introduced on the basis of analysis of social media and website data, only 20 percent gave credible responses. Even the purpose for which the retailers monitored and analyzed website and social media activities revealed the weak link, that is, only 20 percent did it with the intention of collecting customer data to inform marketing strategy, in contrast with between 60 and 100 percent who did it for reasons ranging from handling customer complaints to advertising products. To complement this inform, only 20 percent of supermarkets engaged in database marketing, signaling that a very low usage of cross-selling potential of BI technology was in place. The consequence of this is that when asked whether the use of social media network analysis had resulted in more customers buying their products, only 40 percent agreed strongly, while on the had use of predictive analytics to enhance market penetration returned a score of 0 percent for strongly agree. 60 percent agreed somewhat agree while 40 percent were neutral on the question of predictive analytics for scaling up market penetration.

\section{CONCLUSION AND IMPLICATIONS}

The study set out to establish the influence BI technology on the marketing strategies of large supermarkets in Kenya. From the findings, it is concluded that the state of influence of Business Intelligence technology on marketing strategies of large supermarkets in Nairobi is in its infancy. The parameters used to gauge the extent of adoption of BI technology for marketing by supermarkets were usage of data in supermarket data warehouses, for instance, segmentation and database marketing, and sources of data for marketing purposes. Also considered were usage of customer data from supermarket website and social media, and introduction of new products based on analysis of data warehouses and online sources. Others were the extent of usage of particular BI technologies such as classification, decision trees, Artificial Neural Networks, Naïve Bayes and recommendation software; and the motive for monitoring activity on websites and social media sites

The results suggested that large supermarkets in Nairobi have not sufficiently adapted their marketing strategies to a rapidly transforming marketing scene that is now largely premised on highly accurate and individualized data analytics tools. These tools can analyze new forms of both structured and unstructured data including geospatial and textual information, in real time and at individualized levels thus facilitating micro-segmentation. Traditional marketingwhich used market surveys to collect data about a handful of variables-is still the default mode for the industry. Newer methods informed by analytics techniques that are dynamic and in many cases supported by the ubiquity of mobile telephones, are yet to be adopted 


\section{RECOMMENDATIONS}

Firstly, there is need for supermarkets to use data from social media to inform marketing strategy rather than only for reputation management and complaints handling as is currently the case. For example, supermarkets should take full advantage of the wide popularity of social media to promote their merchandize by using Network Analysis to identify social influencers who are highly socially networked. Through these individuals, supermarkets can enhance market penetration of their products in a variety of ways. Social media could also be used to identify opportunities for introducing new products and services. Conversation on the social platforms can be subjected to text analytics to identify highly talked about topics including products not currently served by the market. Products thus introduced have high likelihood of take up hence reduction of business risk.

Supermarkets possess vast amounts of individual customer data that should be used not only to enhance customer loyalty through rewards, but also for predicting next time of particular purchases and detection of the stage in the life cycle where an individual is. The latter can be used for predictive purposes to identify when a person is nearing a given stage to trigger sending of promotional messages of products that an individual is likely to buy when they eventually reach that next stage.

There is also need for supermarkets to diversify their sources of data to enrich the data warehouse for greater accuracy in segmentation. Segmentation must not be based only or largely on demographic data as it appears to be the status quo. Putting up online shopping (ecommerce) can facilitate the collection of diverse customer data such as type of device used for browsing, web pages most frequented by a user or users, the order of web pages visited, time spent on each page and the number of people visiting each page. This clickstream data can be used to, among other things, enhance online shopping experience by optimizing the website to align with customer traits. These and other data types can help in fine-tuning recommendation software to more accurately suggest which other products a customer can buy based on what they have bought already or what else others buying similar products are buying. The clickstream data may also be analyzed for a new product or service which when introduced will not disappoint in terms of sales.

The study found that the surveyed supermarkets used a limited set of BI technology, especially Market Basket Analysis. There are others that were not used by any of the participating retail outlets. These are Artificial Neural Networks (ANN), Decision Trees, Classification and Naïve Bayes, some of which could be configured for automated real-time personalized segmentation of customers based on a vast and complex array of variables, both structured and unstructured. Additionally, ANN can be used for predictive purposes and to track a customer's change in behavior and profile over time. The supermarkets are strongly advised to adopt these technologies

\section{ACKNOWLEDGEMENT}

We would like to acknowledge the School of Business, University of Nairobi where the study was anchored for the technical and material support which enabled us carry out this study

\section{References}

Aanderud, T. \& Hall, A. (2011). Building business intelligence using SAS: Content development examples. North Carolina, USA: SAS Institute Inc.

Agarwal, P. (2014). Benefits and issues surrounding data mining and its application in the retail industry. International Journal of Scientific and Research Publications, 4(7), 1-5.

Barney, J.B. (1991). Firm resources and sustained competitive advantage. Journal of Management, 17(1), 99-120. 
Barney, J.B. (2002). Gaining and sustaining competitive advantage. (2nd ed.), Upper Saddle River, New Jersey: Prentice Hall.

Brown, B., Schuler, S. \& Sikes, J. (2012, January). Capturing the upside of technology threats. In McKinsey Center for Business Technology (Ed.), Perspectives on digital business (pp 7-17). McKinsey and Company

Burton, B., Geishecker, L., Schlegel K., Hostmann, B., Austin, T., Herschel, G., Soejarto, A. \& Rayner, N. (2006). Business intelligence focus shifts from tactical to strategic. Stamford, U.S.A: Gartner Research

Constantiou, I. \& Kallinikos, J. (2015). New games, new rules: Big data and the changing context of strategy. Journal of Information Technology, 30 (1), 44-57.

Davis, F.D. (1989). Perceived usefulness, perceived ease of use, and user acceptance of information technology. MIS Quarterly, Business Intelligence Research, 13(30), 319-340.

Drucker, P. F. (1973). Management: Tasks, responsibilities and practices. Toronto: Fitzhenry \& Whiteside Ltd.

Duff \& Phelps (2016). Industry insights: Food retail industry insights

Dyche (2012), in Kitchin, R. (2014). Big data, new epistemologies and paradigm shifts. Big Data \& Society, AprilJune(2014), 1-12, DOI: 10.1177/2053951714528481

Fotaki, G., Spruit, M., Brinkkemper, S. \& Meijer, D. (n.d.). Exploring big data opportunities for Online Customer Segmentation. (Technical report) Utrecht University.

Gieskes H. (2000). Competitive intelligence at Lexis-Nexis. Competitive Intelligence Review, 11(2): 4-11.

Kenya Vision 2030: The popular version.

Hosmer, D.W. (2000). Applied logistic regression. (2nd ed.). New York: John Wiley and Sons

Institute for Business Intelligence (n.d.) Verständnis von Business Intelligence. In K a r r a s c h T. F.

Kahalekar, S.A.,\& Patil, S. (2016). An analysis on predictive analytics and data mining in telecom and automobile in Maharashtra. International Journal of Advanced Computational Engineering and Networking, 4(2), 88-90.

Kaplan, R \& Norton, D. (2006) Creating the strategy-focused organization. Boston, Massachusetts: Harvard Business School Press

Kar, A.K., Pani, A.K. \& De, S.K. (2010). A study on using business intelligence for improving marketing efforts. Business Intelligence Journal, 3(2), 141-150.

Kenya National Bureau of Statistics (2017). Economic survey 2017.

Khan, R.A. \& Quadri, S.M.K. (2012). Business intelligence: An integrated approach. Business Intelligence Journal, 5(1), 64-70.

Kothari, C.R. (2004). Research methodology: Methods and techniques. (2nd ed.). Jaipur, India: New Age International Publishers.

Kotler, P. \& Armstrong, G. (2012). Principles of marketing. (14th ed.). Pearson, Prentice Hall

Kotler, P., Armstrong, G., Saunders, J. \& Wong, V. (1999). Principles of marketing: Second European edition. New Jersey, USA: Prentice Hall.

Kotler, P. (1997). Marketing management: Analysis, planning, implementation, and control. (9th Ed). Upper Saddle River: Prentice Hall.

Leavey, J. (2013, September). Social media and public policy: What is the evidence? London: Alliance for Useful Evidence

Liu, F. \& Lee, H. J. (2010). Use of social network information to enhance collaborative filtering performance. Expert Systems with Applications, 37, 4772-4778,

Manyika, J., Chui, M., Burghin, J., Brown, B., Dobbs, R., Roxburgh, C. \& Byers, A.H. (2011, May). Big data: The next frontier for innovation, competition, and productivity, McKinsey Global Institute, McKinsey and Company

Mbaluka, W. (2013, November). Big data management and business value in the commercial banking sector in Kenya (Master thesis).

Mithamo, M.K., Marwa, M. \& Letting, N. (2015). An analysis of challenges facing major supermarkets that emanate from the changing environment: A case of Kenyan large cities. Journal of Business Management and Economics, $3(4)$. 
Nketia, M.O. (2016). Business intelligence (BI): A system to optimize business performance. International Journal of Business \& Management, 4(9), 218-224.

Porter, M.E. (1980). Competitive strategy: Techniques of analyzing industries and competitors. (26-31). New York: The Free Press

Redzepovic, D. \& Theodoros, P. (2015). Big data-driven innovation: The role of big data in new product development, (Master Thesis).

Reinartz, W., Dellaert, B., Krafft, M., Kumar, V. \& Varadarajan, R. (2011). Retailing innovations in a globalizing retail market environment. Journal of Retailing, 87(1), 59-66. doi:10.1016/j.jretai.2011.04.009

Ruhi, U. (2014). Social media analytics as a business intelligence practice: Current landscape \& future prospects. Journal of Internet Social Networking \& Virtual Communities, 2014(2014): 1-12. doi:10.5171/2014.920553.

Saunders, M., Lewis, P. \& Thornhill, A. (2009). Research methods for business students (5 ${ }^{\text {th }}$ Ed.). Essex, England: Pearson Education.

Soukhoroukova, A., Spann, M. \&, and Skiera, B. (2010). Sourcing, filtering, and evaluating new product ideas: An empirical exploration of the performance of idea markets, Journal of Product Innovation Management. (Pre-print)

Sudhakar, K., Prasath, S.R.G. \& Kumar V.A.(n.d.). Modern marketing practice. IOSR Journal of Business and Management, 34-37

Vercellis, C. (2009). Business intelligence: Data mining and optimization for decision making. John Wiley \& Sons, Ltd.

Vojtovič, S., Navickas, V. \& Gruzauskas, V. (2016, June). Strategy of sustainable competitiveness: Methodology of real-time customers' segmentation for retail shops. Journal of Security and Sustainability Issues, 5(4).

Walliman, N. (2011). Research methods: The basics. New York, USA: Routledge.

Winston, W. (2014). Marketing analytics. Indianapolis: John Wiley \& Sons.

Yelkur, R. \& Herbig, P. (1996). Global markets and the new product development process. Journal of Product and Brand Management, 5(6), 38-47

Zhang, X., Chen, X. \& Ding, L. (2013). Self-service product innovation based on data mining technology.

International Journal of Database Theory and Application, 6(5), 105-118, DOI:

http://dx.doi.org/10.14257/ijdta.2013.6.5.10 